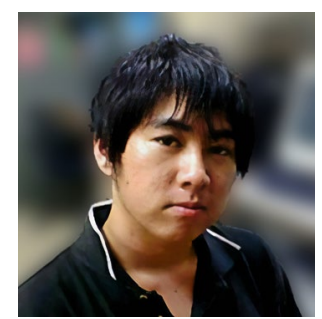

\title{
Publish but perish regardless in Japan
}

\author{
$\mathrm{PhD}$ students and early career researchers are severely underfunded, explains \\ Yuki Yamada, an Associate Professor in Psychology. Paired with biased selection criteria \\ and unreasonable demands, this not only harms Japan's young scientists, but presents \\ a threat to academia itself.
}

Credit: Keiko Ihaya

$\mathrm{R}$ eportedly, Japan's scholarly output has relatively declined over the past decade. This decline is a natural consequence of Japan's treatment of graduates and postdocs-the most active researchers-who receive little support and recognition. Worse still, the academic environment prevents them from conducting intensive research.

A significant obstacle to productivity is the financially precarious situation in which many graduate students find themselves. Graduate students are not employed by their labs in Japan and can receive neither salary nor benefits from the University. When I was a graduate student, I sometimes depended on consumer finance to pay my living and travel expenses. Because I could not secure food expenses due to heavy debts, I was eating cheap bean sprouts every day. At present, it seems that only rich people or those willing to go into debt can study in Japanese graduate schools. At national universities, the entrance fee to a graduate school is more than an average university graduate earns in a month, in addition to which graduate students must pay annual fees that are nearly double this entrance fee. Student loans from the government (called 'scholarships') often bear interest. Young researchers are always burdened by their financial circumstances.

The Japan Society for the Promotion of Science (JSPS) offers research fellowships to young scientists. However, there is an obvious flaw in the fellowship system. While the salary for JSPS fellows in a doctoral course is 200,000 yen monthly, the average starting salary for master's graduates in 2018 was 238,700 yen monthly. In other words, the salary of JSPS fellows is lower than the average salary earned by others of the same cohort. In contrast to their peers, graduate students have neither social insurance nor pension. They can only take part-time jobs permitted by the JSPS (e.g., research assistant positions), earning an income of about 25,000 yen for 20 hours of additional work per month, which almost equals the cost of commuting from a neighbouring town to university. This is the fate of top-class young researchers who have passed tough selection procedures; in 2019 , only $18.9 \%$ of applicants in the social sciences field, including experimental psychology, were granted JSPS fellowships. In sum, the expenses of taxes and tuition whittle away graduate students' income almost entirely. Anyone can imagine the burden of getting married and having children under these circumstances. Young researchers with no money will have to either borrow money or quit academia.

At the same time, the expectations of graduate students to be all-rounders are exceptionally high and the balance between treatment on the job and required ability is severely tilted. The following conditions may be used to recruit an Assistant Professor in psychology on a 1-year contract: (1) high level of proficiency in natural, medical and social sciences, humanities, and statistics at a teachable level; (2) multiple professional qualifications in clinical psychology; (3) practical experience; (4) overseas experience; and (5) the ability to perform psychological experiments, programming, qualitative research and admissions. Because young researchers feel compelled to agree to all these conditions, they are forced to perform the tasks needed to achieve such broad competence. Published work has almost nothing to do with this type of recruitment because such young researchers are not expected to study, but perform miscellaneous tasks. Nepotism is still strong, and selection is often a one-horse race with extremely short calls and limited recruitment conditions. Many opportunities to become a part time lecturer, which is a clear advantage in later job applications, are bound to having worked in big labs.

However, publications are important at least in psychology, because they are regarded as an output approved by academia. Researchers without publications are treated as if they did not exist. In their race to publish, graduate students face wellknown biases that can posit substantive disadvantages. The chaperone effect (the phenomenon that it is easier to publish in selective journals with a famous co-author on the paper) and the Matthew effect (the phenomenon that the rich get richer) widen the gap in achievements such as papers, awards and grants. When I evaluate candidates, I instead focus on what they are doing apart from co-authoring papers with big-lab primary investigators, but many young researchers on the academic periphery cannot find jobs regardless of the number of papers they published. Losing highly-trained peers who love psychology for these reasons is sad, and constitutes a huge loss of human resources. It is academia's suicide.

Hiring all-rounders as described above presents another big issue. Psychological research has become more sophisticated and complicated in various aspects such as measurement and computational methods. Old-school all-rounders cannot do everything. It is necessary to form research groups that give specialists with outstanding skills their rightful place and to optimize teams flexibly and dynamically. In soccer, congeries of 11 playmakers cannot beat a team of highly coordinated experts. It is desirable for academia to be such that young researchers can say, "I am not an allrounder; this is how I can shine." Evaluating researchers by the number of first-author papers and journal-impact factors is no longer meaningful. To begin with, the influence of nepotism and the primary investigator's prestige must be completely eliminated from evaluations. Thus, it is critical to advance the development of a system that specifically and fairly evaluates how a researcher has contributed to research (e.g., CRediT, https://www.nature.com/ articles/d41586-019-02084-8) and that will support the progress of specialists.

First and foremost, however, is the pivotal issue of ensuring that young researchers in Japan can live a stable life.

\section{Yuki Yamada}

Kyushu University, Fukuoka, Japan.

e-mail:yamadayuk@gmail.com

Published online: 10 October 2019

https://doi.org/10.1038/s41562-019-0729-9

Competing interests

The author declares no competing interests. 